\title{
HUBUNGAN ANTARA PENGGUNAAN GADGET DENGAN KECERDASAN (INTELEKTUAL, EMOSIONAL, SPIRITUAL DAN SOSIAL) ANAK USIA SEKOLAH DI SDK ST. THERESIA ATAMBUA II
}

\author{
ABSTRAK \\ Lenny Maria Nahak ${ }^{1)}$ Pius A.L Berek ${ }^{2)}$, Elfrida Dana Riwoerohi ${ }^{3)}$, MariaFatimah W. A Fouk ${ }^{4)}$ \\ ${ }^{122) 344)}$ Prodi Keperawatan UNIMOR Kampus Atambua.JlWehor Kabuna Haliwen Atambua Nusa Tenggara \\ Timur. Post 85711. Email:lennynahak13@gmail.com. Phone 082144916086
}

Perkembangan Teknologi Informasi (TI) merupakan suatu hasil dari semakin berkembangnya pengetahuan manusia yang dapat memberikan perubahan pada pola kehidupan manusia. Salah satu bentuk TI yang sering digunakan adalah Gadget. Penggunaan gadget dapat memberikan dampak positif dan dampak negatif. Karena gadget menyajikan berbagai hal menarik, tak heran kini anak - anak menjadi pengguna gadget terbanyak. Penelitian ini bertujuan untuk mengetahui karakteristik pengguna gadget dan hubungan antara penggunaan gadget dengan kecerdasan intelektual, emosional, spiritual serta sosial anak usia sekolah yang dilihat dari segi orang tua. Penelitian ini menggunakan metode kuantitatif cross sectional untuk mengidentifikasi hubungan antara penggunaan gadget dengan kecerdasan (intelektual, emosional, spiritual dan sosial). Sampel diambil menggunakan teknik acidental sampling. Instrumen yang digunakan adalah kuisioner. Uji statistik menggunakan Chi Square test yang bermakna pada $\mathrm{P}<0,05$ dan diperoleh hasil yaitu pada variabel kecerdasan intelektual $\mathrm{P}=0,042$, kecerdasan emosional $\mathrm{P}=0,044$, kecerdasan spiritual $\mathrm{P}=$ 0,069 dan kecerdasan sosial $\mathrm{P}=0,021$. Kesimpulan dari penelitian ini yaitu ada hubungan yang bermakna antara penggunaan gadget dengan kecerdasan intelektual, emosional, dan sosial tetapi tidak ada hubungan yang bermakna antara penggunaan gadget dengan kecerdasan spiritual. Oleh karena itu peran orang tua sangat dibutuhkan dalam mengawasi buah hati ketika menggunakan gadget.

Kata kunci : penggunaan gadget, kecerdasan intelektual, emosional, spiritual, sosial.

\author{
ABSTRACK \\ Lenny Maria Nahak ${ }^{1)}$ Pius A.L Berek ${ }^{2)}$, Elfrida Dana Riwoerohi ${ }^{3)}$, Maria Fatimah W. A Fouk ${ }^{4)}$ \\ ${ }^{122334)}$ Nursing Program at University of Timor, Atambua Campus. Jl Wehor Kabuna Haliwen Atambua East \\ Nusa Tenggara.Post 85711. Email: lennynahak13@gmail.com.Phone 082144916086
}

The development of Information Technology (IT) is a result of the growing development of human knowledge that can provide changes to the patterns of human life. One form of IT that is often used is the gadget. The use of gadgets can have a positive and negative impact. Because the gadget presents a variety of interesting things, it's no wonder now children become the most gadget users. This study aims to determine the characteristics of gadget users and the relationship between the use of gadgets with intelligence, emotional, spiritual and social school-age children in terms of parents. This study uses a quantitative cross sectional method for the relationship between the use of gadgets and intelligence (intellectual, emotional, spiritual and social). Samples were taken using accidental sampling techniques. The instrument used is a questionnaire. Statistical tests using the challenging Chi Square test at $P<0,05$ and the results obtained on intellectual intelligence variables $P=0.042$, emotional intelligence $P=0.044$, spiritual intelligence $P=$ 0.069 and social intelligence $P=0.021$. The conclusion of this study is that there is a relationship between the use of gadgets and intellectual intelligence, emotional intelligence, and social intelligence, but there is no relationship between the use of gadgets and spiritual intelligence. Therefore, the role of parents is needed in the compilation of children who use gadgets.

Keywords: use of gadgets, intellectual intelligence, emotional, spiritual, social. 


\section{PENDAHULUAN}

Perkembangan

Teknologi

Informasi (TI) merupakan suatu hasil dari semakin berkembangnya pengetahuan manusia yang dapat memberikan perubahan pada pola kehidupan manusia. TI memberikan beberapa kemudahan yang dapat digunakan untuk menyelesaikan beberapa permasalahan manusia dalam hal pekerjaan, komunikasi, tugas sekolah dan lain sebagainya sehingga mendorong manusia untuk menggunakan TI. Dengan berbagai macam kemudahan yang ditawarkan, bukan berarti TI sepenuhnya tidak memiliki kekurangan. TI dapat menjadi dua mata pisau untuk perkembangan manusia, dapat memberikan dampak positif untuk kehidupan sehari - hari atau dapat menjadi dampak negatif bila digunakan tidak sesuai porsinya (Saputra, et al.,2017).S

Salah satu bentuk TI yang sering digunakan adalah gadget atau handphone (smartphone). Gadget adalah alat elektronik yang mudah dibawa ke mana saja untuk keperluan komunikasi dan mengetahui informasi. Gadget kini telah mengalami perkembangan yang sangat pesat. Awalnya gadget hanya dapat digunakan untuk kepentingan komunikasi, namun kini gadget dapat digunakan untuk melakukan apapun yang orang inginkan. Selain untuk berkomunikasi, gadget banyak digunakan karena dapat menyajikan berbagai media berita, jejaring sosial, hobi, bahkan hiburan (Wulandari, 2018). Hal ini membuat gadget tidak hanya digunakan oleh orang dewasa (22 tahun ke atas) dan remaja (12-21 tahun), tapi anak-anak (711 tahun) juga menggunakannya dan lebih ironisnya lagi gadget digunakan oleh anak usia dini (3-6 tahun) yang seharusnya belum layak untuk menggunakan gadget (Widiawati \& Sugiman, 2014 dalam Manumpil, et al.,2015).

Masa anak - anak adalah masa di mana semua informasi dapat diterima dengan mudah lalu dikembangkan secara alami. Pada masa ini anak mulai untuk menciptakan, mengembangkan, dan memanipulasi sesuatu, mengembangkan rasa kompetensi dan ketekunan. Didasari hal ini, anak - anak usia 5-12 tahun menjadi pengguna terbanyak dalam kemajuan dari teknologi dan informasi ini. Tidak heran jika anak usia 5-12 tahun dikatakan sebagai generasi multi-tasking (Ameliola \& Nugraha, 2013 dalam Manumpil, et al,2015).

Penggunaan gadget atau alat-alat yang dapat dengan mudah terkoneksi dengan internet ini mengalami peningkatan dari waktu ke waktu. Saat ini kurang lebih 45 juta orang menggunakan internet, di mana 9 juta di antaranya menggunakan ponsel untuk mengakses internet. Padahal pada tahun 2001, jumlah pengguna internet di Indonesia hanya $1 / 2$ juta penduduk. Jumlah ini semakin bertambah karena semakin mudah didapat serta terjangkaunya harga dari gadget (Sanjaya \& Wibhowo, 2011 dalam Manumpil, et al., 2015). Tentunya hal ini berdampak positif bila digunakan sesuai porsinya, tetapi dapat juga berdampak negatif bila digunakan tidak sesuai porsinya terutama pada pengguna gadget usia anak - anak.

Menurut Chusnah (2017), gadget memberikan dampak positif pada pola pikir anak yaitu mampu membantu anak dalam mengatur kecepatan bermainnya, mengolah strategi dalam bermain, dan membantu meningkatkan kemampuan otak kanan anak selama dalam pengawasan yang baik. Akan tetapi, dibalik kelebihan tersebut lebih dominan 
dampak negatif yang berpengaruh terhadap perkembangan anak yaitu radiasi dari gadget yang dapat merusak jaringan saraf dan otak, menurunkan daya aktif anak dan kemampuan anak untuk berinteraksi dengan orang lain, serta anak menjadi lebih individual sehingga kurang memiliki sikap peduli terhadap teman bahkan orang lain. Selain itu, dampak negatif lainnya yaitu waktu terbuang sia sia, perkembangan otak anak menjadi terganggu, menghambat kemampuan anak dalam mengekspresikan pikiran, banyak fitur yang tidak sesuai dengan usia anak, miskin akan nilai norma, edukasi dan agama, serta menghilangkan ketertarikan anak pada aktifitas bermain atau melakukan kegiatan lain.

Dengan demikian, gadget memberikan dampak yang berbeda - beda pada setiap anak. Oleh sebab itu, peran orang tua sangat diperlukan dalam mengajari dan mengawasi perkembangan anak. Tetapi pada faktanya, di era teknologi yang semakin canggih ini, orang tua menganggap bahwa gadget merupakan salah satu alat yang dapat digunakan untuk mendidik anak, sehingga bukan menjadi hal yang aneh lagi apabila anak mendapat fasilitas gadget dari orang tuanya. Di samping itu, pada penelitian awal yang dilakukan peneliti di beberapa sekolah dasar terdekat, penulis mendapatkan hasil bahwa di SDK St. Theresia Atambua II dari 624 orang siswanya sebagian besar berasal dari keluarga dengan taraf ekonomi menengah ke atas. Mereka menggunakan gadget untuk berkomunikasi dengan orang tua, bermain games dan tak sedikit yang menggunakan gadget untuk mengakses media sosial. Berdasarkan fenomena tersebut, penulis merasa tertarik untuk meneliti lebih lanjut tentang Hubungan Antara Penggunaan Gadget dengan
Kecerdasan (Intelektual, Emosional, Spiritual dan Sosial) Anak Usia Sekolah di SDK St. Theresia Atambua II.

\section{METODE}

Penelitian ini menggunakan pendekatan deskriptif kuantitatif cross secsional. Penelitian ini bertujuan untuk mengidentifikasi hubungan antara penggunaan gadget dengan kecerdasan (intelektual, emosional, spiritual dan sosial) anak usia sekolah di SDK St. Theresia Atambua II.

Responden merupakan orang tua siswa SDK St. Theresia Atambua II yang diambil dengan cara accidental sampling dan perhitungan rumus solvin menghasilkan 244 responden.

Alat pengumpulan data dalam penelitian ini adalah kuisioner dengan 33 pernyataan yang diuji validitas dan reliabilitasnya di SDK St. Angela Atambua. Uji validitas dan reliabilitas menggunakan perhitungan alpha cronbach dengan hasil $\alpha=0,742(\alpha>$ $0,60)$ dan menghasilkan 32 pernyataan yang dinyatakan valid dan dapat digunakan untuk penelitian selanjutnya.

\section{HASIL PENELITIAN}

Analisa Univariat

Tabel 1

Distribusi Frekuensi Penggunaan Gadget di SDK St. Theresia Atambua II

\begin{tabular}{lccc}
\multicolumn{3}{c}{$(\mathbf{N}=\mathbf{2 4 4})$} \\
\hline Variabel & Kategori & Frekuensi & $\begin{array}{c}\text { Percentase } \\
(\%)\end{array}$ \\
\hline Penggunaan & & & 94,67 \\
Gadget & Ya & 231 & 5,33 \\
\hline Total & Tidak & 13 & 100 \\
\hline Sum & & 244 &
\end{tabular}

Sumber : Data Primer, 2019

Berdasarkan tabel di atas, dapat diketahui bahwa anak di SDK St. Theresia Atambua II sebanyak 94,67\% menggunakan gadget dan 5,33\% tidak menggunakan gadget. 
Tabel 2

Gambaran Kecerdasan Intelektual Anak Setelah Menggunakan Gadget di SDK St. Theresia Atambua II ( $N=244)$

\begin{tabular}{lccc}
\hline Variabel & Kategori & Frekuensi & $\begin{array}{c}\text { Percentase } \\
(\%)\end{array}$ \\
\hline Kecerdasan & Tidak Baik & 150 & 61,5 \\
Intelektual & Baik & 94 & 38,5 \\
\hline Total & & 244 & 100 \\
\hline
\end{tabular}

Sumber : Data Primer, 2019

Berdasarkan tabel di atas, dapat diketahui bahwa terdapat 61,5\% anak di SDK St. Theresia Atambua II memiliki kecerdasan intelektual yang tidak baik setelah menggunakan gadget, dan terdapat 38,5\% anak memiliki kecerdasan intelektual baik setelah menggunakan gadget.

\section{Tabel 3}

Gambaran Kecerdasan Emosional Anak Setelah Menggunakan Gadget di SDK St. Theresia Atambua II

\begin{tabular}{lccc}
\multicolumn{4}{c}{$(\mathbf{N}=\mathbf{2 4 4})$} \\
\hline Variabel & Kategori & Frekuensi & $\begin{array}{c}\text { Percentase } \\
(\%)\end{array}$ \\
\hline Kecerdasan & Tidak Baik & 172 & 70,5 \\
Emosional & Baik & 72 & 29,5 \\
\hline Total & & 244 & 100 \\
\hline Sumber : Data Primer, 2019 & &
\end{tabular}

Berdasarkan tabel di atas, dapat diketahui bahwa terdapat $70,5 \%$ anak di SDK St. Theresia Atambua II memiliki kecerdasan emosional yang tidak baik setelah menggunakan gadget, dan terdapat $29,5 \%$ anak memiliki kecerdasan emosional baik setelah menggunakan gadget.

$$
\text { Tabel } 4
$$

Gambaran Kecerdasan Spiritual Anak Setelah Menggunakan Gadget di SDK St. Theresia Atambua II

\begin{tabular}{lccc}
\multicolumn{3}{c}{$(\mathbf{N}=\mathbf{2 4 4})$} \\
\hline Variabel & Kategori & Frekuensi & $\begin{array}{c}\text { Percentase } \\
(\%)\end{array}$ \\
\hline Kecerdasan & Tidak Baik & 147 & 60,2 \\
Spiritual & Baik & 97 & 39,8 \\
\hline Total & & 244 & 100 \\
\hline Sumber : Data Primer, 2019 & &
\end{tabular}

Berdasarkan tabel di atas, dapat diketahui bahwa terdapat $60,2 \%$ anak di SDK St. Theresia Atambua II memiliki kecerdasan spiritual yang tidak baik setelah menggunakan gadget, dan terdapat 39,8\% anak memiliki kecerdasan spiritual baik setelah menggunakan gadget.

Tabel 5

Gambaran Kecerdasan Sosial Anak Setelah Menggunakan Gadget di SDK St. Theresia Atambua II

$(\mathrm{N}=\mathbf{2 4 4})$

\begin{tabular}{lccc}
\hline Variabel & Kategori & Frekuensi & $\begin{array}{c}\text { Percentase } \\
(\%)\end{array}$ \\
\hline Kecerdasan & Tidak Baik & 136 & 55,7 \\
Sosial & Baik & 108 & 44,3 \\
\hline Total & & 244 & 100 \\
\hline Sumber : Data Primer, 2019 & &
\end{tabular}

Sumber : Data Primer, 2019

Berdasarkan tabel di atas, dapat diketahui bahwa terdapat 55,7\% anak di SDK St. Theresia Atambua II memiliki kecerdasan intelektual yang tidak baik setelah menggunakan gadget, dan terdapat $44,3 \%$ anak memiliki kecerdasan intelektual baik setelah menggunakan gadget.

\section{Analisa Bivariat}

Tabel 6

Hubungan Penggunaan Gadget dengan Kecerdasan Intelektual di SDK St. Theresia Atambua II

$(\mathrm{N}=\mathbf{2 4 4})$

\begin{tabular}{|c|c|c|c|c|c|c|c|c|}
\hline \multirow{3}{*}{$\begin{array}{c}\text { Variab } \\
\text { el }\end{array}$} & \multicolumn{4}{|c|}{ Kecerdasan Intelektual } & \multirow{2}{*}{\multicolumn{2}{|c|}{ Total }} & \multirow{3}{*}{$\begin{array}{c}\text { OR } \\
(95 \% \\
\text { CI })\end{array}$} & \multirow{3}{*}{$\begin{array}{c}\mathrm{P} \\
\text { Value }\end{array}$} \\
\hline & \multicolumn{2}{|c|}{$\begin{array}{c}\text { Kategori } \\
\text { Tidak Baik }\end{array}$} & \multicolumn{2}{|c|}{$\begin{array}{c}\text { Kategori } \\
\text { Baik }\end{array}$} & & & & \\
\hline & $\mathrm{N}$ & $\%$ & $\mathrm{~N}$ & $\%$ & $\mathrm{~N}$ & $\%$ & & \\
\hline Penggu & & & & & & & 0,275 & 0,042 \\
\hline naan & & & & & & & $(0,060$ & \\
\hline Gadget & & & & & & & - & \\
\hline $\mathrm{Ya}$ & 139 & 60,2 & 92 & 39,8 & 231 & 100 & $1,268)$ & \\
\hline Tidak & 11 & 84,6 & 2 & 15,4 & 13 & 100 & & \\
\hline Total & 150 & 61,5 & 94 & 38,5 & 244 & 100 & & \\
\hline
\end{tabular}

Berdasarkan tabel di atas, dapat diketahui bahwa hasil analisa hubungan antara penggunaan gadget dengan kecerdasan intelektual diperoleh hasil bahwa ada sebanyak $92 \quad(39,8 \%)$ anak yang menggunakan gadget memiliki kecerdasan intelektual yang baik. Sedangkan di antara anak yang tidak menggunakan gadget ada $2(15,4 \%)$ anak memiliki kecerdasan intelektual yang baik. Hasil uji statistik diperoleh nilai $\mathrm{P}=$ 0,042, maka dapat disimpulkan bahwa ada perbedaan proporsi kecerdasan 
intelektual antara anak yang menggunakan gadget dengan anak yang tidak menggunakan gadget (ada hubungan yang signifikan antara penggunaan gadget dengan kecerdasan intelektual). Hasil analisa lanjutan diperoleh pula nilai $\mathrm{OR}=0,275$, artinya anak yang tidak menggunakan gadget mempunyai peluang 0,275 kali untuk memiliki kecerdasan intelektual yang baik dibandingkan dengan anak yang menggunakan gadget.

Tabel 7

Hubungan Penggunaan Gadget dengan Kecerdasan Emosional di SDK St. Theresia Atambua II

$(\mathrm{N}=\mathbf{2 4 4})$

\begin{tabular}{|c|c|c|c|c|c|c|c|c|}
\hline \multirow{3}{*}{$\begin{array}{c}\text { Variab } \\
\text { el }\end{array}$} & \multicolumn{4}{|c|}{ Kecerdasan Intelektual } & \multirow{2}{*}{\multicolumn{2}{|c|}{ Total }} & \multirow{3}{*}{$\begin{array}{c}\text { OR } \\
(95 \% \\
\text { CI) }\end{array}$} & \multirow{3}{*}{$\begin{array}{c}\mathrm{P} \\
\text { Value }\end{array}$} \\
\hline & \multicolumn{2}{|c|}{$\begin{array}{c}\text { Kategori } \\
\text { Tidak Baik }\end{array}$} & \multicolumn{2}{|c|}{$\begin{array}{c}\text { Kategori } \\
\text { Baik }\end{array}$} & & & & \\
\hline & $\mathrm{N}$ & $\%$ & $\mathrm{~N}$ & $\%$ & $\mathrm{~N}$ & $\%$ & & \\
\hline $\begin{array}{l}\text { Penggu } \\
\text { naan }\end{array}$ & & & & & & & $\begin{array}{l}0,704 \\
(0,188\end{array}$ & $\begin{array}{l}0,044 \\
*\end{array}$ \\
\hline Gadget & & & & & & & & \\
\hline Ya & 162 & 70,1 & 69 & 29,9 & 231 & 100 & $2,638)$ & \\
\hline Tidak & 10 & 76,9 & 3 & 23,1 & 13 & 100 & & \\
\hline Total & 172 & 70,5 & 72 & 29,5 & 244 & 100 & & \\
\hline
\end{tabular}

Sumber : Data Primer 2019; * bermakna pada $\alpha<0,05$

Berdasarkan tabel di atas, dapat diketahui bahwa hasil analisa hubungan antara penggunaan gadget dengan kecerdasan emosional diperoleh hasil bahwa ada sebanyak $69 \quad(29,9 \%)$ anak yang menggunakan gadget memiliki kecerdasan emosional yang baik. Sedangkan di antara anak yang tidak menggunakan gadget ada $3(23,1 \%)$ anak memiliki kecerdasan emosional yang baik. Hasil uji statistik diperoleh nilai $\mathrm{P}=$ 0,044, maka dapat disimpulkan bahwa ada perbedaan proporsi kecerdasan emosional antara anak yang menggunakan gadget dengan anak yang tidak menggunakan gadget (ada hubungan yang signifikan antara penggunaan gadget dengan kecerdasan emosional). Hasil analisa lanjutan diperoleh pula nilai $\mathrm{OR}=0,704$, artinya anak yang tidak menggunakan gadget mempunyai peluang 0,704 kali untuk memiliki kecerdasan emosional yang baik dibandingkan dengan anak yang menggunakan gadget.

Tabel 8

Hubungan Penggunaan Gadget dengan Kecerdasan Spiritual di SDK St. Theresia Atambua II $(\mathrm{N}=\mathbf{2 4 4})$

\begin{tabular}{|c|c|c|c|c|c|c|c|c|}
\hline \multirow{3}{*}{$\begin{array}{c}\text { Variab } \\
\text { el }\end{array}$} & \multicolumn{4}{|c|}{ Kecerdasan Intelektual } & \multirow{2}{*}{\multicolumn{2}{|c|}{ Total }} & \multirow{3}{*}{$\begin{array}{c}\text { OR } \\
(95 \% \\
\text { CI })\end{array}$} & \multirow{3}{*}{$\begin{array}{c}\mathrm{P} \\
\text { Value }\end{array}$} \\
\hline & \multicolumn{2}{|c|}{$\begin{array}{c}\text { Kategori } \\
\text { Tidak Baik }\end{array}$} & \multicolumn{2}{|c|}{$\begin{array}{c}\text { Kategori } \\
\text { Baik }\end{array}$} & & & & \\
\hline & $\mathrm{N}$ & $\%$ & $\mathrm{~N}$ & $\%$ & $\mathrm{~N}$ & $\%$ & & \\
\hline $\begin{array}{l}\text { Penggu } \\
\text { naan }\end{array}$ & & & & & & & $\begin{array}{l}0,659 \\
(0,197\end{array}$ & 0,069 \\
\hline $\begin{array}{l}\text { Gadget } \\
\mathrm{Ya}\end{array}$ & 138 & 59,7 & 93 & 40,3 & 231 & 100 & $\begin{array}{l}- \\
2,205)\end{array}$ & \\
\hline Tidak & 9 & 69,2 & 4 & 30,8 & 13 & 100 & & \\
\hline Total & 147 & 60,2 & 97 & 39,8 & 244 & 100 & & \\
\hline
\end{tabular}

Sumber : Data Primer 2019; * bermakna pada $\alpha<0,05$

Berdasarkan tabel di atas, dapat diketahui bahwa hasil analisa hubungan antara penggunaan gadget dengan kecerdasan spiritual diperoleh hasil bahwa ada sebanyak $93 \quad(40,3 \%)$ anak yang menggunakan gadget memiliki kecerdasan spiritual yang baik. Sedangkan di antara anak yang tidak menggunakan gadget ada $4(30,8 \%)$ anak memiliki kecerdasan spiritual yang baik. Hasil uji statistik diperoleh nilai $\mathrm{P}=$ 0,069, maka dapat disimpulkan bahwa ada perbedaan proporsi kecerdasan spiritual antara anak yang menggunakan gadget dengan anak yang tidak menggunakan gadget (tidak ada hubungan yang signifikan antara penggunaan gadget dengan kecerdasan spiritual). Hasil analisa lanjutan diperoleh pula nilai $\mathrm{OR}=0,659$, artinya anak yang tidak menggunakan gadget mempunyai peluang 0,659 kali untuk memiliki kecerdasan spiritual yang baik dibandingkan dengan anak yang menggunakan gadget. 
Tabel 9

Hubungan Penggunaan Gadget dengan

Kecerdasan Sosial di SDK St. Theresia

Atambua II

$(\mathrm{N}=\mathbf{2 4 4})$

\begin{tabular}{|c|c|c|c|c|c|c|c|c|}
\hline \multirow{3}{*}{$\begin{array}{c}\text { Variab } \\
\text { el }\end{array}$} & \multicolumn{4}{|c|}{ Kecerdasan Intelektual } & \multirow{2}{*}{\multicolumn{2}{|c|}{ Total }} & \multirow{3}{*}{$\begin{array}{c}\text { OR } \\
(95 \% \\
\text { CI })\end{array}$} & \multirow{3}{*}{$\begin{array}{c}\mathrm{P} \\
\text { Value }\end{array}$} \\
\hline & \multicolumn{2}{|c|}{$\begin{array}{c}\text { Kategori } \\
\text { Tidak Baik }\end{array}$} & \multicolumn{2}{|c|}{$\begin{array}{c}\text { Kategori } \\
\text { Baik }\end{array}$} & & & & \\
\hline & $\mathrm{N}$ & $\%$ & $\mathrm{~N}$ & $\%$ & $\mathrm{~N}$ & $\%$ & & \\
\hline $\begin{array}{l}\text { Penggu } \\
\text { naan }\end{array}$ & & & & & & & $\begin{array}{l}0,777 \\
(0,247\end{array}$ & $\begin{array}{l}0,021 \\
*\end{array}$ \\
\hline Gadget & & & & & & & - & \\
\hline Ya & 128 & 55,4 & 103 & 44,6 & 231 & 100 & $2,446)$ & \\
\hline Tidak & 8 & 61,5 & 5 & 38,5 & 13 & 100 & & \\
\hline Total & 136 & 55,7 & 108 & 44,3 & 244 & 100 & & \\
\hline
\end{tabular}

Berdasarkan tabel di atas, dapat diketahui bahwa hasil analisa hubungan antara penggunaan gadget dengan kecerdasan sosial diperoleh hasil bahwa ada sebanyak $103(44,6 \%)$ anak yang menggunakan gadget memiliki kecerdasan sosial yang baik. Sedangkan di antara anak yang tidak menggunakan gadget ada 5 (38,5\%) anak memiliki kecerdasan sosial yang baik. Hasil uji statistik diperoleh nilai $\mathrm{P}=$ 0,021, maka dapat disimpulkan bahwa ada perbedaan proporsi kecerdasan sosial antara anak yang menggunakan gadget dengan anak yang tidak menggunakan gadget (ada hubungan yang signifikan antara penggunaan gadget dengan kecerdasan sosial). Hasil analisa lanjutan diperoleh pula nilai $\mathrm{OR}=0,777$, artinya anak yang tidak menggunakan gadget mempunyai peluang 0,777 kali untuk memiliki kecerdasan sosial yang baik dibandingkan dengan anak yang menggunakan gadget.

\section{PEMBAHASAN}

Hubungan penggunaan gadget dengan kecerdasan intelektual

Berdasarkan hasil analisa didapatkan hasil bahwa proporsi anak yang tidak menggunakan gadget namun memiliki kecerdasan intelektual baik sebanyak 2 anak $(15,4 \%)$ dan yang tidak menggunakan gadget namun memiliki kecerdasan intelektual tidak baik sebanyak 11 anak (84,6\%). Selain itu, proporsi anak yang menggunakan gadget namun memiliki kecerdasan intelektual baik sebanyak 92 anak $(39,8 \%)$ dan yang menggunakan gadget namun memiliki kecerdasan intelektual tidak baik sebanyak 139 anak $(60,2 \%)$. Hasil analisa chi square didapatkan hasil bahwa ada hubungan bermakna antara penggunaan gadget dengan kecerdasan intelektual ( $\mathrm{P}$ value : 0,042).

Hasil penelitian ini sejalan dengan penelitian Saputra et al (2017), perkembangan Teknologi Informasi dapat membuat ketertarikan anak terhadap belajar menjadi menurun dan dapat memberikan pengaruh negatif bagi tingkat prestasi anak. Selain itu penelitian ini sesuai dengan penelitian Nurmalasari (2018) di mana didapatkan hasil gadget memberikan pengaruh ketergantungan dan mempengaruhi nilai prestasi siswa.

Robert dalam Zakiah (2013) mengatakan bahwa kecerdasan intelektual adalah kemampuan untuk memperoleh pengetahuan, memanggil (recall) pengetahuan yang telah diperoleh dan menggunakan pengetahuan yang telah diperoleh. Pengetahuan yang baik yang diperoleh maka hal - hal baiklah yang ditunjukkan, tetapi jika pengetahuan yang tidak baik yang diperoleh maka hal - hal yang tidak baik pula yang ditunjukkan.

Menurut Chusna (2017), seiring berkembangnya zaman, sekarang aktivitas belajar tidak hanya terfokus dengan buku, namun melalui gadget dapat diakses berbagai ilmu pengetahuan yang diperlukan tanpa repot untuk ke perpustakaan yang mungkin jauh dijangkau. Namun terkadang, anak - anak salah menggunakannya, gadget digunakan hanya untuk bermain game 
maupun berselancar di dunia maya sehinga ketertarikan pada belajar menjadi menurun.

Peneliti berpendapat bahwa, lebih banyak responden yang mempunyai kecerdasan intelektual yang tidak baik diakibatkan oleh penggunaan gadget tanpa pengawasan orang tua sehingga gadget digunakan tidak dengan semestinya. Gadget yang awalnya diberikan dengan alasan unuk komuniksai beralih fungsi menjadi teman bermain anak. Apalagi anak yang menggunakan gadget untuk berselancar di dunia maya, setelah mendapatkan teman dari dunia maya yang enak diajak berbincang bincang maka anak akan lupa dengan teman bahkan hal lain di dunia nyata. Selain itu, dunia maya sendiri menyediakan banyak konten yang menarik. Anak akan menggunakan rasa penasaran mereka untuk membuka konten - konten tersebut. Hal ini membuat anak lupa waktu. Anak akan meninggalkan dunia bermain dan melupakan tugas pokok mereka untuk belajar ataupun mengerjakan tugas sekolah.

Tetapi anak yang juga menggunakan gadget dan kecerdasan intelektualnya baik, peneliti berpendapat bahwa anak - anak tersebut menggunakan gadget dengan semestinya. Selain karena memiliki kecerdasan intelektual yang baik dari lahir, anak - anak ini menggunakan gadget setelah menyelesaikan tugas sekolah. Dengan atau tanpa pengawasan orang tua, anak anak ini menggunakan gadget sesuai dengan kebutuhan mereka dan tidak melupakan tugas pokok sebagai anak sekolah. Pengetahuan baik yang didapat dari gadget diaplikasikan dalam kehidupan sehari - hari dengan baik pula.

Hubungan penggunaan gadget dengan kecerdasan emosional
Berdasasrkan hasil analisa didapatkan hasil bahwa proporsi anak yang tidak menggunakan gadget namun memiliki kecerdasan emosional baik sebanyak $23,1 \%$ dan yang tidak menggunakan gadget namun memiliki kecerdasan emosional tidak baik sebanyak 76,9\%. Selain itu, proporsi anak yang menggunakan gadget namun memiliki kecerdasan emosional baik sebanyak 29,9\% dan yang menggunakan gadget namun memiliki kecerdasan emosional tidak baik sebanyak $70,1 \%$. Hasil analisa chi square didapatkan hasil bahwa ada hubungan bermakna antara penggunaan gadget dengan kecerdasan emosional ( $\mathrm{P}$ value : 0,044$)$.

Hasil penelitian ini tidak sesuai dengan penelitian Saputra et al (2017), berdasarkan hasil penelitiannya didapatkan bahwa kecerdasan emosional dipengaruhi oleh berbagai macam faktor, salah satunya yaitu kondisi lingkungan sekitar dan kebiasaan. Tumbuh kembang anak yang disertai dengan penggunaan gadget nyatanya tidak berpengaruh negatif terhadap tingkat emosional karena orang tua masih dapat mengendalikan penggunaan gadget dalam kegiatan anak - anak mereka.

Menurut Goleman dalam Efendi (2005), kecerdasan emosional adalah kecerdasan mengelola emosi pada diri sendiri dan dalam hubungan dengan orang lain. Dengan kata lain kecerdasan emosional adalah kecerdasan mengendalikan diri. Anak yang sering menggunakan gadget tidak mampu mengendalikan diri dengan baik akibat dari kecenderungan untuk sendiri dalam memainkan gadgetnya. Saat memainkan gadget, anak secara tidak langsung dituntut untuk berfokus pada gadgetnya sehingga emosi akan meningkat ketika diganggu orang lain. 
Selain itu, menurut Suwarsih dalam hasil seminar Pengaruh gadget pada perkembangan anak mengatakan bahwa, salah satu perilaku terkait emosi anak saat sedang bermain gadget adalah anak cenderung bersikap membela diri dan marah ketika ada upaya untuk mengurangi atau menghentikan penggunaan gadget. Dan juga salah satu dampak negatif pemakian gadget menurut Suwarsih adalah anak akan sulit mengontrol emosi karena terganggunya fungsi PFC (pre frontal cortex).

Peneliti berpendapat bahwa, kecerdasan emosional anak menjadi tidak baik setelah menggunakan gadget karena gadget memberikan efek kecanduan. Saat anak sudah tergantung dengan gadget anak akan lupa untuk bermain. Padahal, aktivitas bermain dapat mengasah emosi anak karena saat bermain anak akan belajar untuk mengalah, belajar untuk minta maaf saat salah, belajar untuk kembali berdamai dengan teman agar bisa bermain bersama kembali, anak akan tertawa bersama saat ada sesuatu yang lucu dan lainnya. Saat anak tergantung dengan gadget, anak tidak dapat belajar mengenal diri karena tidak ada penilaian yang didengar dari teman, anak tidak dapat mengendalikan diri karena saat marah tidak ada balasan dari gadget, anak akan susah berempati pada sesama dan tidak memiliki keterampilan sosial karena anak tidak mau bersosialisasi dengan sesama.

\section{Hubungan penggunaan gadget dengan kecerdasan spiritual}

Berdasasrkan hasil analisa didapatkan hasil bahwa proporsi anak yang tidak menggunakan gadget namun memiliki kecerdasan spiritual baik sebanyak $30,8 \%$ dan yang tidak menggunakan gadget namun memiliki kecerdasan spiritual tidak baik sebanyak $69,2 \%$. Selain itu, proporsi anak yang menggunakan gadget namun memiliki kecerdasan spiritual baik sebanyak 40,3\% dan yang menggunakan gadget namun memiliki kecerdasan spiritual tidak baik sebanyak 59,7\%. Hasil analisa chi square didapatkan hasil bahwa tidak ada hubungan bermakna antara penggunaan gadget dengan kecerdasan intelektual ( $\mathrm{P}$ value : 0,069 ).

Menurut Kyle dan Charman (2014), perkembangan moral dan spiritual selama masa usia sekolah terbentuk secara konstan dan berasal dari keluarga berlandaskan agama dan keyakinan yang dianut. Selain itu menurut Saputra et al (2017), penggunaan gadget tidak memberikan dampak yang buruk pada kecerdasan spiritual. Kedua hal ini mendukung hasil penelitian bahwa tidak ada hubungan antara penggunaan gadget dengan kecerdasan spiritual.

Misbach dalam Zakiah (2013) mengatakan bahwa kecerdasan spiritual adalah kecerdasan tertinggi dalam diri dan merupakan landasan yang diperlukan untuk memfungsikan kecerdasan intelektual dan kecerdasan emosional secara efektif. Pendapat ini pun mendukung hasil penelitian dimana hasil analisa kecerdasan intelektual dan kecerdasan emosional tidak jauh berbeda dengan hasil dari kecerdasan spiritual.

Peneliti berpendapat bahwa, kecerdasan spiritual seorang anak merupakan hasil dari didikan keluarga. Gadget bukan merupakan unsur luar yang dapat mengubah hasil dari didikan orang tua. Hasil kecerdasan spiritual yang tampak dalam hasil penelitian tidak ada hubungannya dengan penggunaan gadget, tetapi tampak bahwa anak yang menggunakan gadget masih lebih banyak yang memiliki kecerdasan spiritual yang 
tidak baik. Maka hal ini menjadi pekerjaan rumah bagi orang tua agar lebih banyak menanamkan nilai - nilai positif dalam kehidupan keluarga terutama pada anak sehingga menjadi lebih baik lagi. Pepatah mengatakan "apa yang ditanam, itulah yang dituai”, dengan demikian sebagi orang tua jika ingin anak menjadi baik dikemudian hari, maka hal - hal baiklah yang diberikan karena masa anak - anak adalah masa untuk menanam hal hal baik.

\section{Hubungan penggunaan gadget dengan kecerdasan sosial}

Berdasarkan hasil analisa

didapatkan hasil bahwa proporsi anak yang tidak menggunakan gadget namun memiliki kecerdasan sosial baik sebanyak $38,5 \%$ dan yang tidak menggunakan gadget namun memiliki kecerdasan sosial tidak baik sebanyak 61,5\%. Selain itu, proporsi anak yang menggunakan gadget namun memiliki kecerdasan sosial baik sebanyak $44,6 \%$ dan yang menggunakan gadget namun memiliki kecerdasan sosial tidak baik sebanyak 55,4\%. Hasil analisa chi square didapatkan hasil bahwa ada hubungan bermakna antara penggunaan gadget dengan kecerdasan intelektual ( $\mathrm{P}$ value : 0,021).

Hasil penelitian ini sesuai dengan hasil penelitian Wahyu Novitasari bahwa ada hubungan yang bermakna antara penggunaan gadget dengan interaksi sosial. Namun, Saputra et al (2017) mengatakan bahwa teknologi informasi memberikan dampak yang baik bagi kecerdasan sosial anak. Anak - anak menjadi lebih mudah dalam mendapatkan teman baru dan hubungan dengan teman sekitar leingkungan masih terjalin baik. Anak - anak masih bisa menghabiskan waktu untuk bermain dengan teman - teman seusianya karean ada pengawasan dari orang tua terhadap anak.

Chusna (2017) mengatakan, selain untuk berkomunikasi gadget juga digunakan untuk bersosialisasi. Gadget memiliki banyak fitur dan aplikasi yang tepat untuk dapat berbagi berita, kabar dan cerita. Sehingga dengan pemanfaatan yang tepat, maka dapat menanmbah teman dan menjalin hubungan dengan kerabat yang jauh tanpa harus bertemu langsung. Namun di sisi lain, gadget pada anak - anak dapat mebuat perilaku yang negatif antara lain, anak tidak suka bergaul atau bermain di luar rumah dengan teman sebayanya, anak meninggalkan dunia bermain demi menyendiri untuk bermain gadget. Hal ini membuat anak lebih individuali dan tidak peka terhadap lingkungan sekitarnya.

Peneliti berpendapat bahwa, hasil penelitian ini menunjukkan bahwa dunia sekarang adalah dunia teknologi di mana anak - anak sedikit demi sedikit meninggalkan permainan tradisional digantikan dengan permainan canggih dalam gadget dan anak lebih tertarik bermain dengan teman lain di dunia maya melalui gadget. Saat anak tidak memainkan gadget dan bermain dengan temannya anak akan lebih cepat merasa bosan karena bermain dengan teman temannya tidak sama dengan apa yang sering dimainkan dalam gadgetnya. Selain itu anak juga tidak tahu bersosialisasi yang baik dengan sesama disekitarnya, anak akan melupakan sopan santun yang diajarkan dan tidak santun dalam memperlakukan teman sebayanya. Selain itu, ada orang tua yang senang karena anaknya lebih tenang saat memainkan gadget dan anak tidak berpanas - panasan di luar rumah untuk bermain atau anak tidak mengganggu 
pekeraan rumah orang tuanya tanpa khawatir dengan sosialisasi anaknya.

\section{KESIMPULAN}

Peneliti menyimpulkan bahwa ada hubungan bermakna antara penggunaan gadget dengan kecerdasan intelektual, kecerdasan emosional, dan kecerdasan sosial tetapi tidak ada hubungan bermakna antara penggunaan gadget dengan kecerdasan spiritual. Dengan demikian, peneliti mengharapkan orang tua agar lebih memahami kecerdasan anak dan memberikan pengawasan yang ketat dan tegas pada anak dalam menggunakan gadget serta lebih mendekatkan diri pada anak agar anak tidak menjadikan gadget sebagai sahabat yang akhirnya berdampak tidak baik bagi kehidupan anak selanjutnya.

\section{DAFTAR PUSTAKA}

Chusna, Puji Asmaul. 2017. Pengaruh Media Gadget Pada Perkembangan Karakter Anak. Jurnal. STIT Al-Muslihun.

Efendi, Agus. 2005. Revolusi Kecerdasan Abad 21 : Kritik MI, EI, SQ, AQ dan Succesful Intelligence Atas $I Q$. Bandung. Alfabeta (Anggta IKAPI)

Hastono, Sutanto Priyo. 2007. Analisis Data. Jakarta. Fakultas Kesehatan Masyarakat, Univarsitas Indonesia

Kozier, Barbara et al. 2010. Buku Ajar Fundamental Keperawatan : Konsep, proses, dan praktik. Jakarta. Penerbit Buku Kedokteran : EGC
Kuswana, Wowo Sunaryo. 2014. Biopsikologi Pembelajaran Prilaku. Bandung. Alfabeta

Kyle, Terri dan Susan Carman. 2014. Buku Ajar Keperawatan Pediatri.Volume 1. Jakarta. Penerbit Buku Kedokteran : EGC

Manumpil, Beauty et al. 2015. Hubungan Penggunaan Gadget Dengan Tingkat Prestasi Siswa Di SMA Negeri 9 Manado. Ejurnal Keperawatan (e-Kep). Volume 3 No 2.

Misbach, Ifa Hanifah. 2008. Antara IQ, EQ dan SQ - Pelatihan Nasional Guru Se - Indonesia. Universitas Pendidkan Indonesia. Jakarta.

Novitasari, Wahyu. 2016. Dampak Penggunaan Gadget Terhadap Interaksi Sosial Anak Usia 5 - 6 Tahun. Jurnal Paud Teratai. Volumpe 05, No 03.

Nurmalasari dan Devi Wulandari. 2018. Pengaruh Gadget Terhadap Tingkat Prestasi Siswa SMPN Satu Atap Pakisjaya Karawang. Jurnal Ilmu Pengetahuan dan Teknologi Komputer. Volume 3, No 2.

Nursalam. 2008. Konsep Dan Penerapan Metodologi Penelitian Ilmu Keperawatan : Pedoman Skripsi, Tesis, Olah Instrumen Penelitian Keperawatan. Jakarta. Salemba Medika 
Riduwan, DR.,M.B.A. 2010. Belajar Mudah Penelitian:untuk Guru_ Karyawan dan Peneliti Pemula. Bandung. Alfabeta.

Saputra, Gilang Wisnu et al. 2017. Pengaruh Teknologi Informasi Terhadap Kecerdasan (Intelektual, Spiritual, Emosional, dan Sosial) Studi Kasus Anak -Anak. Jurnal Sistem Informasi. volume 10, No 2.

Sastroasmoro, Sudigdo \& Sofyan Ismael. 2002. Dasar - Dasar Metodologi Penelitian Klinis. Edisi 2. Jakarta. Sagung Seto

Siregar, Syofian. 2013. Metode Penelitian Kuantitatif : Dilengkapi Dengan Perbandingan Perhitungan Manual \& SPSS. Edisi 1. Jakarta. Kencana Prenadamedia Group

Suyadi. 2014. Teori pembelajaran Anak Usia Dini Dalam Kajian eurosains. Bandung. PT Remaja Rusdakarya

Zakiah, Farah. 2013. Pengaruh Kecerdasan Intelektual, Kecerdasan Emosional dan Kecerdasan Spiritual Terhadap Pemahaman Akuntansi. Skripsi. Jurusan Akuntansi Fakultas Ekonomi Universitas Jember. 